\title{
Defining tree taper: A challenge for growth and yield modelling in Ontario
}

\author{
by W.T. Zakrzewski ${ }^{1}$
}

Key words: modelling stem profile, taper model evaluation, plantation, stand density, tree slimness, growth and yield modelling in Ontario

Mots clés : modélisation du profil de tronc, évaluation du modèle de réduction progressive, plantation, densité de peuplement, minceur des arbres, modélisation de la croissance et de la production en Ontario

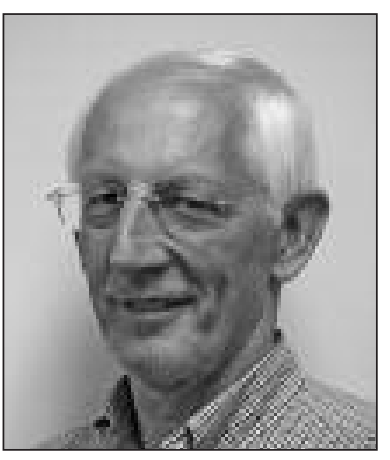

W.T. Zakrzewski
I would like to comment on a paragraph in the article "Ontario's forest growth and yield modelling program: Advances resulting from the Forestry Research Partnership" by M. Sharma, J. Parton, M. Woods, P. Newton, M. Penner, J. Wang, A. Stinson and F.W. Bell, published in The Forestry Chronicle, Vol. 84, No. 5 (2008). In the article, the authors say: "Historically, OMNR's G \& Y [growth and yield] program has relied on taper equations developed from data derived from natural stands. One such commonly used taper equation in Ontario was presented by Zakrzewski (1999). Although sufficient for natural stands, using these equations to calculate individual stem volumes for plantationgrown trees has the potential to introduce bias (generally an overestimate), and this bias will be magnified when used in association with Ontario's new benchmark yield curves."

Normally, I would ignore these speculative statements and treat them as unfortunate phrasing. However, I am concerned that the conclusions based on the statements by the authors have (1) confused foresters about taper modelling, and will lead to (2) continued inefficient research on the influence of stand density on tree taper. These negative consequences, I believe, should be noted.

Let me comment on the text. My first point is that taper models are not developed "from data," and certainly not from a specific data set (e.g., natural stands, plantations). The taper functions suggested by many authors to describe (or even better: explain) tree stem morphology are formal hypotheses. Measurements from any tree stem from any forest in the world can be used to define (calibrate, fit), but are not sufficient to develop, the taper model. It is highly desirable that a model is a representation of reality that offers the possibility of acquiring new information about that reality. Claiming that the model by Zakrzewski (1999) was "developed from data derived from natural stands" is false (see additional details on taper model derivation in Zakrzewski and MacFarlane 2006). The authors apparently confuse "a model as a hypothesis about stem morphology" and "a calibrated taper function defined for a specific data set." If one does not distinguish between these, confusion among readers is likely, if not a given. Lack of clarity in explaining modelling nuances happens; however, following up with unsubstantiated conclusions indicates that this was not the case in the discussed paragraph.

The false starting point is used by the authors for expanded speculations. With not a single citation in support of their conclusion, the authors evaluate Zakrzewski's (1999) model as "sufficient for natural stands" and claim that the model (in general?) has potential to introduce bias for plantation-grown trees. Nothing wrong with this; which statistical model in the world does not have this potential? Unfortunately, the authors assume that "potential" is "reality" (suspected, thus, guilty), and come up with a prophetic (no citations) assurance that the bias "will be magnified when used in association with Ontario's new benchmark yield curves." Logically, the very practical question arises: Is Zakrzewski's (1999) model able to adequately reflect taper of tree stems from plantations?

Pitt and Lanteigne (2008) seem not to agree with Sharma et al's (2008) conclusions. In the Canadian Journal of Forest Research (balsam fir and red spruce study) they wrote: "Thus, Zakrzewski's (1999) model appeared capable of compensating for the different stand densities in the study through tree-specific expressions of $H D R(s=1+H D R)$." The allometric expression $H D R$ is a height/diameter ratio: trees in dense stands competing for light tend to be slimmer with the crown bases located relatively higher than those growing in open stands. The difference between plantations and natural stands is the "controlled" vs. "natural" growth environment of trees. The abiotic component of forest site (climate, soil-one has to

\footnotetext{
${ }^{1}$ Provincial Forest Science Modeller, Ontario Forest Research Institute, 1235 Queen Street East, Sault Ste. Marie, Ontario P6A 2E5, E-mail: Voyteck.zakrzewski@ontario.ca.
} 
be careful when saying "abiotic" with respect to soil) is the same in both cases. Individual tree competitive status (its growth environment) is, on average, different. "Plantation" is a very vogue term. If we "plant and go," a plantation may very soon become an understocked stand or one with undesired tree species composition. Site preparation, weed control, fertilization, and thinning make a difference. As a result, in "managed plantations," height growth of individual trees is faster at younger ages; this results in some kind of a trade-off between vertical and horizontal wood sequestration, which depends on stand density (related but not equivalent to number of trees per unit area or stand basal area). At the individual tree level a competitive status (crown features) is crucial for wood sequestration, thus, the importance of HDR. I hypothesize that a tree species-specific Maximum Slimness Line (MSL), a concept similar to that used in constructing stand density management diagrams, should help even more than $H D R$ in studying stand density influence on tree taper. The authors say "biased for plantations" without defining "plantations." It seems that they are referring to a stand density issue, and Pitt and Lanteigne's (2008) results contradict the statement.

Examining the influence of a stand density on tree taper is not a trivial task and should not be limited to presenting better fit (or lack of fit) statistics. For foresters, it is important that the suggested solution is both sound and practical.

Soundness involves suggesting an appropriate design for a taper model. Modellers should strive, I believe, to assure a model's mathematical tractability and not to treat, e.g., locations of points of inflection of the taper curve (so important in taper/density studies) as a "side effect" of the cross-sectional area regression fit. A mathematically tractable model should be able to produce, in a closed form, equations describing such locations (in addition to sectional, cumulative or total volumes, or height locations of given merchantability limit), which can be treated as dependent variables in simultaneously defining (fitting) a system of compatible equations. Such an approach is rooted in two main purposes of defining taper models: (1) minimizing prediction errors for variables of interest (not exclusively stem cross-sectional area), and 2) revealing a "true" stem profile pattern without "imposing" weaknesses of the suggested model on the data.

Practicality, in addition to ease of model use, also requires considering the cost of model application. Stage (2003) stated that "Choice of a model for exploring options for managing forest ecosystems depends on the decision space..." Such space is constrained by economic factors since model initiation depends on the possibility of collecting measurements required by a model. Using allometric relationships to minimize cost of model application has a long history in forestry. In taper models, using HDR to account for a stand density is the proven option. Using stand parameters for that purpose (increased predictive power of the taper model) should produce some gain to compensate for additional cost.

Recently, Sharma and Parton (2009) tested the influence of stand density on tree taper using stem measurement data for Ontario. The authors suggest a model that requires knowledge of both tree and stand parameters, which is expensive for the potential user and disregards Pitt and Lanteigne's (2008) results. As the rationale for choosing the model the authors use an argument unrelated to the purpose of the model (accounting for density): dubious "superiority" in accuracy and precision of their model. Li and Weiskittel (2009) from the University of Maine examined 11 taper models, including Sharma and Parton's (2009). Several taper models, including those with $H D R$, performed consistently better than the latter (in terms of volume and diameter predictions) for balsam fir, white pine and red spruce.

I believe that further studies are needed, but more cautious "model endorsements," especially of one's own models,

Table 1. Suggested criteria for evaluating taper model

Taper models

\begin{tabular}{|c|c|c|c|c|c|}
\hline $\begin{array}{l}\text { Model } \\
\text { features }\end{array}$ & Kozak 1988 & $\begin{array}{c}\text { Valentine } \\
\text { and Gregoire } \\
2001\end{array}$ & $\begin{array}{l}\text { Sharma and } \\
\text { Zhang } 2004\end{array}$ & $\begin{array}{c}\text { Max and } \\
\text { Burkhart } \\
1976\end{array}$ & $\begin{array}{c}\text { Zakrzewski } \\
1999\end{array}$ \\
\hline
\end{tabular}

Precisely and accurately predict tree sizes along a stem

Predict diameters for every height

location on a stem

Integrate cross-sectional area model to produce closed solution for stem (or section); analytically define cumulative stem volume

Analytically define total tree height

based on given sizes on tree stem

Analytically define location of merchantability limit on a tree stem

Analytically define points of inflection on a stem

Define a stem surface in a closed form

Benchmark data sample-specific evidence

Yes

No

No

No

No

No
No

No

No

No

No

No
No

No

No

No

No

No
Yes

Yes

Yes

Yes

Yes

Yes

No 
should be made. More rigorous scientific and economic criteria should be used to set the directions of provincial growth and yield research in the area of taper modelling. Economic concerns in particular should be considered when setting provincial research priorities. Too often, expanded data collection programs do not contribute to increased efficiency of modeling products. In general, corporate programs are very often driven by employment opportunities rather than by efficiency of research.

The results of taper modelling in Ontario (and obviously other growth and yield modelling efforts) seem to require more scrutiny. Should we provide a benchmark data set (e.g., via a Web site), to be used whenever a taper model is fitted? Should we ask (see Table 1) model structure-related questions when evaluating taper models (such as why the model by Valentine and Gregoire [2004] does not predict diameter equal to zero at the total height location, or why the model presented by Sharma and Parton [2009] cannot predict tree diameter at ground level?). In my view, we should expand the standards set by Kozak and Smith (1993). I realize the list of criteria in Table 1 is incomplete-there is a need for accounting for a variable form, and a benchmark data set requires thorough discussion. Is it, however, a realistic suggestion? We need an objective reference, helpful for interpreting any taper modelling result, especially when the presented solutions may imply higher costs (and not necessarily "superior" results) for the users. In applied science, the cost is important indeed.

In any case, publishing unsubstantiated statements such as those discussed here is, in my opinion, unacceptable.

\section{References}

Kozak A. 1988. A variable-exponent taper equation. Can. J. For. Res. 18: $1363-1368$.

Kozak A. and J.H.G. Smith. 1993. Standards for evaluating taper estimating systems. For. Chron. 69(4): 438-444.

Li, R. and A.R. Weiskittel. 2009. Development and evaluation of regional taper and volume equations for the primary conifer species in the Acadian Region of North America. Annals of Forest Science. Forthcoming.

Max, T.A. and H.E. Burkhart. 1976. Segmented polynomial regression applied to taper equations. For. Sci. 22: 283-289.

Pitt, D. and L. Lanteigne. 2008. Long-term outcome of precommercial thinning in northwestern New Brunswick: growth and yield of balsam fir and red spruce. Can. J. For. Res. 38: 592-610.

Sharma, M. and J. Parton. 2009. Modeling stand density effects on taper for jack pine and black spruce plantations using dimensional analysis. For. Sci. 55: 268-282.

Sharma, M. and S.Y. Zhang. 2004. Variable-exponent taper equations for jack pine, black spruce, and balsam fir in eastern Canada. Can. J. For. Res. 198: 39-53.

Stage, A.R. 2003. How forest models are connected to reality: evaluation criteria for their use in decision support. Can. J. For. Res. 33: 410-421.

Valentine, H.T. and T.G. Gregoire. 2001. A switching model of bole taper. Can. J. For. Res. 31: 1400-1409.

Zakrzewski, W.T. 1999. A mathematically tractable stem profile model for jack pine in Ontario. North. J. Appl. For. 16(3): 138-143. Zakrzewski, W.T. and D.W. MacFarlane. 2006. Regional stem profile model for cross-border comparisons of harvested red pine (Pinus resinosa Ait.) in Ontario and Michigan. For. Sci. 52(4): 468-475. 